\title{
The Effectiveness of Special Schools in the Teaching of Children with Learning Disabilities in South Africa
}

\author{
Nilford Hove \\ Gauteng Department of Education, South Africa \\ nilfordhove@yahoo.com
}

Doi:10.5901/mjss.2014.v5n20p1903

\begin{abstract}
This paper reports on the findings of a study that was aimed at gauging the effectiveness of Special Schools in the teaching of children with learning disabilities in the South African context. This was necessitated by the rise in advocacy for the policy of inclusivity and the push thereto for its implementation in schools. The study was attempting to answer to the question: To what extent are special schools responsive to the needs of children with learning disabilities to unjustify the call for their abolishment? Results of the study indicated that special schools are more effective in terms of the students' outcomes. Moral and self-esteem is even higher in special schools for both students and teachers in those settings. The study was undertaken through the qualitative design. Six special education teachers were purposefully chosen to participate in the study. Data were presented through instructive vignettes and recommendations were given in the study.
\end{abstract}

Keywords: Learning Disabilities, Self-Esteem, Inclusive Education, Placement, Special Education Classrooms, Individual Educational Programs, Mainstream Classes, Curriculum

\section{Introduction}

After the attainment of democracy in 1994, South Africa sought to redress the inequalities and imbalances in the education sector whose outlook was mainly enshrined in the remnants of the apartheid system. Special Schools as Resource Centers Briefing Document (2010), affirms to the above when it notes that the apartheid era was fraught with inequalities, including in the treatment of people who experienced barriers, to interacting fully in society. One of the key steps taken then was the introduction of an inclusive education system that is aimed at ensuring the attainment of quality education by students with disabilities in the same mainstream classes as those without disabilities. This was on the backdrop of world conferences such as the Salamanca statement (1994) which stated that those with special educational needs must have access to regular schools which should accommodate them within child centered pedagogy.

In view of the above, it can be noted that Inclusive Education was mainly about including the previously excluded in the mainstream education system because of their disabilities. This was in part to fulfill the demands to equalize the opportunities in as much as it was to correct the past imbalances caused by the apartheid regime. Inclusive education is ideal to promote the freedoms, equalities and rights in accordance with the spirit and ethos of liberal constitutional democracies (Sukhrai, 2006). To address this, Education White Paper 6 (2001) suggests the systematic moving away from using disabilities to segregate learners with disabilities and instead seeking ways to include them at every level of educational practice.

This raise questions as to whether the drifting away from special schools towards inclusion is as practical a move as it is in theory. This is a critical move that we would need to answer in earnest as we seek to establish whether special schools are effective enough in the pedagogics of students with learning disabilities. From so many written literatures, it sounds like the move is more of a humanitarian call to do away with segregation. It however does not seem to be going deeper to question whether the same students benefit holistically in the mainstream classes as they would in the special schools (classes). Although constitutional measures set the stage for desegregation to unfold at schools, it did not go further to interrogate the quality of contact, not only in the personal attitudes of students and teachers but also in the institutional arrangements, policies and ethos of the school (Sayed, 2001:254). In the same vein, Hocutt (1996), notes that inclusion is controversial because of its emphasis on placement rather than what happens in the classroom. Enter classroom.

An ideal education system for a child with a disability is that which empowers that individual to be self-sufficient, be employable, and create his own means of income and his general independence. How then can this be best achieved for 
the child with learning disabilities? Is it wise to allow the child to sit for an academic curriculum in the mainstream classes, though with a watered down curriculum? One is tempted to respond to such questions in the negative form given that the child with disabilities needs to be taught skills that would allow him/her to be independent.

The policy of inclusivity needs a rethink with regards to students with learning disabilities. It should not be merely a case of placement in a view to correct the past injustices. Education and Manpower bureau (2005) indicates to the notion that special schools are well staffed with suitably qualified teachers, most of whom are highly committed and hard working. Arguably, this could be so because they don't need to dedicate some of their teaching schedule to the average and above average as is the case with those in the mainstream classes. Those employed in special schools work hard to provide a secure and caring environment for their students (Education and Manpower Bureau, 2005).

According to Hocutt (1996), studies conducted since 1980 indicate slightly better academic outcomes for students with learning disabilities who are served in special education classrooms. Terman, Lerner and Stevenson (1996) allude to the above in their assertion that many students with learning disabilities perfom academically and have better self-esteem when provided with special services, often in a separate setting. A study of twenty one students with learning disabilities who had been in special education classes and returned to general education showed that the students made small but steady gains in special education, but made no gains in general education (Hocutt 1996).

Sigamoney (1995) posits that large classes are a reality in most South African schools and the number of learners per class could in some cases exceed fifty. This casts a dark shadow over the prospects of a child with disabilities being able to optimally gain in those settings. The classes are so big as to militate against the efforts of individual teachers in those settings to reach out and proffer help to those in need. In addition, the qualifications of teachers in the mainstream classes generally do not atone to the expectations with regards to the teaching of students with learning disabilities. Remediation of the problems of learning in disabled children is a highly specialized subject area which demands specific knowledge and skills from practitioners (Schaik, 2000).

According to Fontana and Lari (2010), the national policy stresses the need for improving post school vocational courses in special education, but maintains that one of the functions of such courses is to promote independent living and to prepare the recipients of special education for employment. In view of the above, an ideal curriculum is one that would dedicate much of the time to skills development in preparation for their employability. However, this cannot be achieved in the mainstream classes as the other students in those classes would require that time for the completion of what is prescribed of them. This, however, is practically possible when they are placed in special classes of their own, where they can manipulate the time tables, attend skills development programs in as much as they would attend to basic numeracy and literacy activities.

\section{Goals of the Study}

The study sought to ascertain the effectiveness of special classes in the teaching of children with learning disabilities. This is on the backdrop of the policy of inclusivity which requires them to be taught in the same class as those who are average and above average. This was done through seeking to give an answer to the question: Are special schools responsive enough to the needs of children with learning disabilities as to unjustify the calls for their abolishment?

\section{Design}

According to Joppe (2000), qualitative research uses a naturalistic approach that seeks to understand phenomena in context-specific settings such as 'real world' setting (where) the researcher does not attempt to manipulate the phenomena of interest. In this study, the researcher used the phenomenological approach. This was done through the use of interviews. Six special education teachers (three males and three females) were purposefully chosen to participate in the study. These six teachers are currently teaching in the special classes. They were specifically chosen because of their knowledge and experience with students with learning disabilities. All the six are black South African teachers teaching at three different schools in Johannesburg South District.

The participants were informed of their right to withdraw from participating should they wish to do so. They were also made aware of the purpose of the study in a bid to do away with suspicions that could arise. Assurance was given that whatever they would say would not be traced back to them, neither would it be divulged to anyone else besides the researcher himself. This was to ensure that both their rights to remain anonymous as well as to treat their information with confidentiality is guaranteed. 


\title{
4. Instrumentation
}

The researcher collected data through interviews. A set of five questions were asked to each participant. The questions bordered around the need to establish both the effectiveness and responsiveness of Special Schools to the needs of students with learning disabilities. These questions related to curriculum, self-esteem, pace of learning, skills training and department of education annual assessments.

\section{Procedure}

The researcher made appointments with each of the six participants. These appointments were all set for the afternoons to guard against interfering with their school days' programs. The interviews were held within the school premises just after their students had left. Permission was sought from the principals concerned to visit the teachers for the interviews. The interviews were held on different days for each teacher because of time constraints. The researcher also asked the participants to be truthful and honest in their responses. Responses that needed clarity were probed further through rephrasing of the questions.

\section{Data Analysis}

Responses from the participants were summarized to give an overview of what the participants said with regards to their feelings, thoughts, experiences and beliefs about the question under study. After going through the responses, three were presented in the form of vignettes.

\section{Results and Discussion}

The results showed that teachers in special classes strongly feel that children with learning disabilities should be taught in special schools and not in mainstream classes. The results were presented in the form of instructive vignettes. Through instructional vignettes, we uncover for ourselves the complexities within each scenario, the implications of actions and the alternatives when connecting theory and practice (Pasque and Aaron, 2012). The use of instructive vignettes allowed for the connections of what is said theoretically and that which is being practically experienced by the participants. Mr. Zulu, a teacher at Orange Farm Special School strongly feels that special schools are more effective in teaching those with learning disabilities and therefore should be pursued. In his responses, Mr. Zulu noted that:

\begin{abstract}
A special class helps the teacher to focus on children's needs as well as teaching them according to their pace of learning. In a special class, the teacher is not distracted by the need to provide for the expectations of other students without disabilities. Children are not looked down upon by their better abled peers or even being openly rebuked for their slowness or incompetencies. The special class helps the child cope with everyday life situations and can be selfsustainable through 'skills training'. If learners are to be improved or prepared for life, the special class is very effective otherwise we will end up with statistics of incompetent students at national examinations who do not have skills to cope with after school life.
\end{abstract}

The response given above shows a strong argument in favor of special classes. These relate to low levels of distractibility on the part of the teachers, appropriate pace of learning as students are mostly uniform in ability as well as the prospects of them not being marginalized and openly rebuked as it would be in mainstream classes. This would result in low self-esteem in those students. Furthermore, there is the view that special classes do cater for skills training and their curriculum helps them to be well prepared for their future self-sustenance.

Ms. Mkhari, is a teacher at a different school as that of Mr. Zulu. Her views on the effectiveness of special schools also suggested that Special schools are very effective in the education of the child with learning disabilities. Ms. Mkhari notes that from her lived experiences:

Mixing learners inclusively worsen the learners with learning disabilities' situation in so far as self-esteem is concerned. If placed in the mainstream class, they start comparing themselves with those with better potentials resulting in them developing a sense of helplessness. At times, as peers, they call each other names and this affects them psychologically. In addition, special schools open up opportunities for skills training for such learners. Well qualified teachers are always found in special schools and they are better skilled in dealing with students with learning disabilities. 
From his experiences, Mr. Khumalo also concurred with the above arguments as he indicated that special schools are the best when it comes to the handling/teaching of students with learning disabilities. In his arguments, he noted that:

\begin{abstract}
Placing students in Special classes enables learners to be helped appropriately. On the contrary, having them in mainstream classes makes it very stressful and demanding for teachers to give appropriate work and activities that cater for different categories of students in those classes. These learners need other skills for survival like Art, Physical Education, collages, fabric painting and gardening/farming. Teachers in the mainstream classes concentrate on teaching students what is prescribed in the curriculum and strives hard to complete the curriculum content on time in preparation for Annual National Assessments. As such, they find those with learning disabilities a derailment towards the achievement of better results for the school. This therefore means they become the neglected lot in those classes.
\end{abstract}

\title{
8. Conclusion
}

The responses given by the participants indicated steep inclination towards special classes/schools. These relate to the uniformity in ability that is certain to be found in the special classes. This is in contrast to the wide diversity in ability that is the case in mainstream classes. Furthermore, special schools offer the students the opportunity to identify their other talents and work towards their perfection in skills training. Self-esteem is also high where there are no other students who tease them or label them as incompetent. Most special schools are manned by qualified teachers making them more dependable as they have received adequate training in those fields.

\section{Recommendations}

According to Frederickson and Cline (2003), children with learning disabilities should be given the opportunity to develop relevant skills as well as to organize classroom events to enable their optimum participation. In view of the above, it is recommended that students with learning disabilities should be taught in their own special classes that optimize their chances of fully participating in the learning processes. When they are alone, they tend to build that confidence because there are no other students who are looking down upon them. The pace and rate for these students will not be stretched by the average and those above average. In as much as we need to prepare them for their daily engagements in their social lives within their inclusive communities from which they come, much more emphasis should be placed on training them for their future independence in the world of work. Yet this can only be achieved in Special Schools setups where their daily routines can be manipulated to accommodate their needs.

The justification for the placement of children with learning disabilities in special schools is underpinned by the fact that their curriculum should include the nurturing of their other talents that are not academic oriented. The inclusion of children with learning disabilities presupposes that by some miracle these students will suddenly become good performers as to be competent enough to pursue the academic curriculum. This is a wrong notion which in a way militates negatively for the cause of those children. Agreeably, a few may prove to be late bloomers but the rest will remain underachievers academically. This argument suggests that, if placed in special classes of their own, the teachers will be able to juggle with their time tables to allow for activities that are not academically inclined. Many students perform better academically and have better self-esteem when provided with special services, often in a separate setting (Terman et al, 1996)

Critiques of special classes may argue that this is tantamount to segregation. However, the aim of special classes should not be viewed as to promote segregative tendencies but rather focused on providing the best for these students. Placing them in inclusive classes can also be viewed as a betrayal of these students with regards to their future lives. For example, the curriculum in the mainstream classes does not allow for time to do manicure as a skill on a daily basis. Neither does it allow for students to focus and be engaged in gardening, art, music, baking and other skills that need to be developed for these students. Instead, the curriculum in these classes is fully academic and aims at making sure that the students are well prepared for the annual assessments. Therefore, mixing these students who have goals that are completely at variance with each other is not advisable. Efficacy of interventions should be assessed in terms of either academic progress or improved social behavioral skills for students with disabilities (Hocutt. 1996).

The difficulty that exists regarding curriculum breadth seems to arise from the absence of a clear statement as to the overall purpose of special education and the lack of an agreed curriculum (Education and Manpower Bureau 2005). This calls for the development of a broader curriculum that will help to prepare the students for independent lives within the communities. Currently, the practice in the mainstream classes are to water down the curriculum content to the levels of those with learning disabilities and in some cases until that student leaves school. That 'watered down' curriculum won't help the child to get employed. In this regard, the curriculum for children with disabilities should focus on skills 
development and this should be done in their own special classes.

Arguments about self-esteem being low when children with learning disabilities are separated from the rest do not hold water. The opposite is true. At a school, where the researcher is currently teaching, students from the mainstream classes often flock to view the beautiful artefacts, beadworks, drawings, collages that are produced by those in special classes. In some cases, students from mainstream classes often request to come and join those in the special classes, being attracted by the products of those with learning disabilities. Understandably those with learning disabilities take pride in their products hence self-esteem is very high in them.

\section{References}

Education and Manpower Bureau (2005) A Study of the Effectiveness of Special Schools, Hong Kong

Fontana D and Lari Z (2010), The curriculum in special needs education in Pakistan Schools, North East Wales Institution, University of Wales

Frederickson, N and Cline, T (2003) special Educational Needs, Inclusion and Diversity, London; Open University press

Hadebe, J.M (1993), Development of special Education in Zimbabwe. A report on special Development in Post-Independence Zimbabwe, Harare: Ministry of Education.

Hocutt A.M (1996) Effectiveness of special Education: is placement the critical factor, Journal Issue: Special Education for students with Disabilities Volume 6 Number 1.

Joppe, M (2000), the Research Process. Retrieved March 20, 2014, from http:/www.ryerson.ca/-mjoppe/rp.htm.

Pasque P.A and Kuntz, A.M (2012), From theoretical language to the intestices of daily Practice. Reducing competency stripping through transformative teaching and learning, Journal of further and higher Education, Alabama Salamanca Statement and framework for action on special needs Education (1994) Salamanca, Spain

Sayed, Y (2001) Post-apartheid educational transformation: Policy concerns and Approaches, UCT Press, Cape Town

Schaik, J.L.V (2000) Children with problems: An Othopedagogical perspective, Pretoria: Van Schaik Publishers

Sigamoney, M.N (2008), Curriculum 2005, A SPACE FOR ALL. An Introduction to inclusive Education, Western Cape: National Book Publishers.

Special schools as Resource centers Briefly Document (2010) Kwazulu-Natal, Department of Education, MiET Africa

Sukhraj (2006), The Implementation and Challenges to Inclusive Education Policy and Practice in South Africa, Durban, University of KwaZulu Natal

Terman, L.D Larner, M.B and Stevenson S.C and Berman R.E (1996), Special Education For students with disabilities: Analysis and Recommendations Journal Issue: Special Education for students with Disabilities Volume 1.

Zindi F (1997), Special Education in Africa, Magadithsane, Tassals 